\title{
MAKNA REPRESENTASI TOKOH ARINI SEBAGAI OBYEK PATRIARKI DALAM FILM ARINI
}

\author{
${ }^{1}$ Angel Purwanti, ${ }^{2}$ Sri Suana \\ 1,2Ilmu Komunikasi, Universitas Putera Batam. Indonesia \\ Angel.Purwanti@puterabatam.ac.id
}

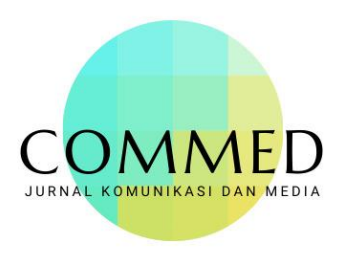

Diterima : 21 Maret 2020; Review : 25 juni 2020; Direvisi Author : 23 juli 2020; Terbit : 14 Agustus 2020

\begin{abstract}
Abstrak
Film Arini mengangkat kisah tentang wanita yang terluka oleh seorang pria, di mana karakter Arini memiliki kelebihan dalam pekerjaan tetapi menderita karena kurangnya masalah dalam kehidupan sosial, yang menjadikan Arini sebagai objek patriarki pria. Dengan latar belakang ini, peneliti tertarik untuk mencari tahu lebih lanjut tentang patriakri karakter Arini dalam film. Ideologi akan ditampilkan pada level ideologi yang menjadikan karakter objek patriarki yang digambarkan dalam film arini. Tujuan dari penelitian ini adalah untuk menunjukkan dan memahami makna representasi sosok perempuan yang digunakan sebagai objek patriarki sebagaimana diwakili dalam Arini dengan metode analisis semiotik John Fiske akan mengungkapkan menggunakan tingkat realitas, representasi, dan ideologi . Penelitian ini berfokus pada kehidupan wanita yang dikendalikan sebagai objek patriarki, termasuk wanita yang lemah, hanya digunakan sebagai objek minat pria, yang mengakibatkan beberapa efek budaya patriarki. Hasil penelitian menunjukkan Arini sebagai objek laki-laki Nick dan Helmi yang membuatnya memiliki perilaku patuh dan patuh serta mengalami efek kekerasan patriarki, subordinasi, dan perceraian.
\end{abstract}

Kata Kunci; Representasi, Patriarki, Semiotik, John Fiske

\section{PENDAHULUAN}

Di era modern saat ini, perkembangan komunikasi sangat cepat, terutama komunikasi melalui media massa. Media massa adalah salah satu kebutuhan dasar untuk memperoleh informasi di era modern saat ini. Dalam penyampaian sebuah pesan bisa langsung ataupun tidak langsung. Media terdiri dari surat kabar, radio, televisi dan film. Keberadaan film kini memiliki makna yang berbeda dibandingkan media massa lainnya. Film adalah media yang menggambarkan bentuk seni kehidupan manusia. Sebagai media, film bukanlah pesan memiliki besa nilai, selain itu sebagai media massa film tidak lepas dari kepentingan dan agenda pembuatnya. (Haryono, 2017, p. 31) 
Film dapat menangkap realitas yang sedang berkembang di layar lebar dalam siaran komunitas. Film memiliki kemampuan untuk menjangkau banyak segmen sosial. Para ahli mengklaim bahwa film ini memiliki potensi untuk mempengaruhi penontonya (Sobur, 2006: 127).

Film Arini bergenre drama romantik mengisahkan seorang wanita lebih tua memiliki karir dan pendidikan yang tinggi tetapi mengalami permasalahan dalam kehidupan sosial terlebih dalam rumah tangga, beberapa tokoh dalam film ini adalah aura kasih sebagai arini menampilkan perempuan lugu dengan sosok mandiri, kuat, modern serta berkelas, morgan oey sebagai nick yang berperan menjadi sosok pemuda santai dan slengekan, Olga Lydia yang berperan sebagai Ira sahabat dekat Arini yang menjodohkan Helmi dengan Arini, Haydar Saliz sebagai Helmi mantan suami Arini. Pembuatan film ini diambil di dua tempat yaitu Yogyakarta dan Jerman.

Tokoh utama dalam film Arini digambarkan sebagai perempuan yang lugu dan penurut pada awalnya kini harus berperan menjadi wanita yang mandiri, berpendidikan dan mempunyai jabatan yang tinggi di tempat ia bekerja. Menurut (Omara, 2004, p. 35) peran wanita
Indonesia dari jaman dahulu memang belum mendapatkan posisi yang sama dengan pria baik itu di wilayah domestik maupun di bidang lapangan pekerjaan, namun seiring perkembangan jaman dan muncul gerakan-gerakan dalam memperjuangkan hak wanita salah satunya R.A Kartini yang memperjuangkan emansipasi perempuan di bidang pendidikan sehingga meluas dalam bidang pekerjaan lainya.

Perempuan rapuh, terluka dan kalah sering ditemukan di media, surat kabar, televisi atau film.(Watie, 2016, p. 1) Fakta bahwa wanita direfleksikan di media adalah hal yang menarik bagi orang yang ingin mendapat keuntungan. Terlebih di sebuah layar lebar perempuan adalah suatu obyek yang sangat menarik untuk dijadikan tema.

Pencipta film mungkin akan meluncurkan adegan porno untuk menarik pemirsa. Sebagai genre film komedi atau horor yang menampilkan tipikal wanita vulgar atau cabul. Dapur, pot, kasur, rambut, bos dan rambut adalah istilah yang sering distereotipkan ke wanita. Dalam sebuah masyarakat yang termasuk dalam sistem patriarki, beranggapan bahwa perempuan hanya dapat bekerja di rumah tangga saja.(Novarisa, 2019, p. 196) 
Menurut (Bourdieu, 2001) budaya ini dimulai pertama kali terlihat saat kesadaran laki-laki dalam memiliki. Ketika orang mulai bertani dan mulai membutuhkan tanah dan peralatan sebagai real estat mereka, yang akhirnya membawa pemahaman tentang kepemilikan pribadi. Perdagangan atau pertukaran dilakukan oleh laki-laki, sehingga penjualan mereka sangat dihargai, tetapi perempuan yang bekerja di wilayah rumah tangga tidak dihargai.

Konsekuensi dari sistem patriarkal (Ramadhan, 2018, p. 81) ini adalah marginalisasi atau proses peminggiran, terlihat dalam kasus program revolusi hijau di orde baru yang pada waktu itu hanya berfokus pada laki-laki, kekerasan yang dimaksud adalah fisik dan mental. kekerasan psikologis, maka ada stereotip adalah gambaran mentah dari individu atau kelompok yang tidak sesuai dengan kebenaran, yang terakhir adalah beban ganda adalah beban yang harus dijalankan wanita di mana ketika perempuan yang bekerja di luar rumah dia harus melakukan pekerjaan rumah.(Radhitya, 2019, p. 205)

Tokoh Arini dalam film diceritakan mengalami kekerasan mental psikologis yang dimana hal ini adalah dampak dari patriarki Arini memiliki trauma dengan suaminya dan sahabatnya yang berselingkuh di belakangnya sampai ia keguguran anak yang dikandungnya. Apalagi ia mengetahui bahwa perkenalan antara ia dan suaminya yang diprakarsai oleh sahabatnya dikarenakan untuk menutupi perselingkuhan keduanya di depan keluarga sahabatnya yang merupakan suatu kepentingan dari lelaki. Disini, tokoh Arini adalah korban dari kondisi yang dimanipulasi oleh tokoh suami dan sahabatnya. Tak hanya itu saja, saat pertama kali bersetubuh dengan Arini, suaminya dalam kondisi mabuk. Ia merasa sakit hati dan hal tersebut menyakiti harga diri dan perasaan wanitanya, dan alasan itulah yang membuatnya merasakan traumatis berkepanjangan dengan sosok laki-laki.

Komunikasi dihasilkan oleh tanda(Hidayat, 2010, p. 225), itulah mengapa tidak asing dalam bidang komunikasi untuk melihat beberapa teori tentang komunikasi berasal dari semiotik. Semiotika adalah sebuah ilmu komunikasi yang menjelaskan tentang tanda-tanda dan makna yang terkandung, menurut john fiske dalam teorinya menyebutkan terdapat tiga area penting dalam studi semiotika (Piliang, 2004, p. 189) yakni tanda itu sendiri, kode sistem yang telah tersusun dengan lambing-lambang dan kebudayaan. 
Di dalam film ini peneliti akan menganalisa kelemahan dan perasaan wanita membuatnya ditampilkan menjadi tokoh yang lemah dan mudah untuk dimanipulasi. Apalagi jika perempuan tersebut memiliki karir yang tinggi, pendidikan yang tinggi, namun kehidupan sosial yang kesepian, sehingga tokoh Arini digambarkan sebagai tokoh perempuan yang pahit, penuh derita, selalu mengalah, dan cenderung dimanipulasi oleh laki-laki. Oleh karena itu, peneliti tertarik untuk melakukan penelitian tentang tokoh Arini sebagai obyek patriarki dari tokoh laki-laki di sekitarnya.

Tujuan dari penelitian ini adalah Untuk menganalisa representasi tokoh "Arini" sebagai objek dalam konsep patriarki.

Representasi adalah gambaran proses interpretasi, pengetahuan atau penjelasan akan pesan secara fisik dalam teori semiotika. Lebih akurat, menurut Danny (2010: 3). "Representasi didefinisikan sebagai penggunaan tandatanda yang diserap, dirasakan, dibayangkan atau dipertimbangkan dalam bentuk fisik."

Sedangkan representasi menurut Fiske yakni mewakili sesuatu yang mengacu pada proses di mana realitas ditransmisikan melalui komunikasi, melalui kata-kata, suara, gambar atau kombinasi. Dalam hal ini, proses pertama memungkinkan untuk menafsirkan dunia dengan membangun rantai korespondensi antara sesuatu dan sistem pemetaan kontekstual. Dalam proses kedua, buat serangkaian korespondensi antara peta konseptual dan bahasa atau simbol yang berfungsi untuk menyajikan konsep tentang sesuatu. Hubungan antara "sesuatu", "pemetaan konseptual" dan "bahasa atau simbol" adalah jantung dari produksi bahasa. Proses yang terjadi bersama ini disebut representasi.

$$
\text { Representasi bekerja }
$$

pada hubungan tanda dan makna. Konsep representasi dapat berubah, sehingga terdapat makna baru. Representasi berubah karena perubahan makna. Selalu ada proses negosiasi dalam arti atau pemaknaan. Dengan demikian, representasi bukan merupakan aktivitas atau proses statis, tetapi proses dinamis yang terus berkembang seiring dengan kemampuan intelektual dan kebutuhan pengguna tanda, yaitu, manusia yang terus juga untuk bergerak dan berubah. Pandangan baru yang menghasilkan makna baru juga merupakan hasil dari pertumbuhan konstruksi pemikiran manusia, melalui representasi 
makna yang dihasilkan dan dikonstruksi. Ini adalah proses pelabelan, praktik yang memberi makna baru.

Representasi adalah aktivitas $\mathrm{p}$ embentukan pengetahuan yang memung kinkan kapasitas otak untuk dilakukan oleh semua orang. Representasi yang jelas seperti menggunakan tanda-

tanda (gambar, suara, dll.) Untuk meng hubungkan, menggambarkan, memotret atau mereproduksi sesuatu yang dilihat, dirasakan, dibayangkan, atau dirasakan dalam bentuk fisik tertentu (Christiyani Martha, 2017, p. 40) Konsep representasi digunakan untuk menggambarkan ekspresi hubungan antara teks (media) dan realitas. Representasi adalah proses di mana anggota budaya menggunakan bahasa untuk menghasilkan makna. Bahasa dalam kasus ini didefinisikan secara luas, yaitu, sebagai sistem apa pun yang menggunakan tanda. Tanda-tanda disini mungkin verbal atau non-verbal.

Representasi dapat didefinisikan sebagai pengguna karakter (gambar, suara, dll.) Untuk membuat, mendeskripsikan, memotret atau menghasilkan sesuatu yang dilihat, dibayangkan, atau dirasakan dalam bentuk fisik tertentu (Syaifullah, 2016). Berdasarkan pengertian ini, representasi adalah proses menghubungkan objek yang sedang diselidiki menjadi sebuah realitas.

$$
\text { Representasi }
$$

yang

dimaksud dalam

penelitian

ini adalah tanda-tanda yang diwujudkan dalam penampilan adegan yang ada di dalam film Arini, terutama mengenai penggambaran tokoh Arini yang diperankan oleh Aura Kasih, dipandang dalam budaya patriarki. Lebih lanjut representasi akan banyak di bahas dalam sub bab teori semiotika.

Fiske, 2004 Dalam kode-kode pertelevisian dijelaskan dalam teori John Fiske, bahwa peristiwa yang ditayangkan telah di enkodekan oleh kode-kode sosial yang terbagi dalam 3 level sebagai berikut: Level pertama adalah realitas (Reality) Kode sosial yang termasuk di dalamnya adalah appearreance (penampilan), Dress (kostum), make-up (riasan) Environment (lingkungan), Behavior (perilaku), Speech (dialog), Gesture (gerakan), expression (ekspresi), sound (suara). Level kedua adalah representasi (Representation), kode sosial yang termasuk di dalamnya adalah kamera (camera) (lightning), Perevisian (editing) : Music (music), Suara (sound). Level Ketiga adalah ideology (Idealogy),kode sosial yang termasuk di dalamnya adalah individualisme (individualism). Patriarki (patriarchy. Ras 
(race), kelas (class),. Materialisme (materialism) Kapitalisme (capitalism).

Dalam analisis ini sesuai dengan teori yang digunakan oleh John Fiske, penulis hanya akan menggunakan kodekode sosial seperti kamera, dialog dalam level representasi. (De Beauvor, 2016) menuliskan perkataan Michelet bahwa seorang laki-laki mampu berfikir dan hidup tanpa adanya campur tangan perempuan, sedangkan perempuan tidak berdaya jika mengerjakan serta memikirkan dirinya tanpa lelaki. Lelaki diposisikan sebagai subyek sedangkan perempuan adalah sosok yang lain.

\section{METODOLOGI PENELITIAN}

Berdasarkan judul serta rumusan masalah pada bab terdahulu dalam penelitian ini, maka jenis penelitian ini adalah kualitatif untuk mendapatkan gambaran yang rinci dan hasil yang lebih mendalam berkaitan dengan penelitian ini.

Penelitian kualitatif dipandang lebih sesuai untuk mengetahui dinamika analisis pada adegan film Arini, Selain itu, penggunaan metode penelitian kualitatif ini tidak lepas dari keinginan peneliti yang ingin mendapatkan informasi-informasi yang lebih mendalam terkait tema penelitian. Penelitian ini menggunakan metode semiotika John Fiske untuk
Menurut pendapat beauvor diatas dapat disimpulkan bahwa perempuan didalam kehidupannya tidak bisa lepas dari kehidupan lelaki bahkan tanpa pertolongan lelaki hal inilah dikatakan sebagai obyek dari seorang lelaki sedangkan lelaki bisa hidup tanpa adanya perempuan karena dia sebagai subyekyang mengatur perempuan. Masalah sosial akibat budaya patriarki menurut (Sakina \& Siti A, 2017, p. 76) ; 1) Kekerasan dalam rumah tangga, 2) Kasus pelecehan seksual, 3) Angka pernikahan dini, 4) Stigma mengenai perceraian. memperoleh makna yang terdapat dalam beberapa scene yang diambil.

Penggunaan metode semiotik milik John Fiske bertujuan untuk mengkaji tanda dan simbol yang terdapat dalam teks. Sesuai dengan penelitian ini, metode semiotika akan dipakai untuk menggali dan mengkaji tanda dan simbol untuk merepresentasikan tokoh Arini sebagai obyek patriarki dalam film.

Data ialah sumber informasi yang peneliti dapatkan melalui penelitian yang dikerjakan. Data yang didapatkan oleh peneliti selanjutnya diolah sehingga informasi dapat bermanfaat bagi pembacanya. Menurut (Lexy J, 2012) 
dapat berupa wawancara atau pengamatan yang merupakan hasil perpaduan dari kegiatan melihat, mendengar dan bertanya. (Moleong, 2012) Sumber data dalam penelitian ini adalah sumber data primer dan sekunder.Data Primer digunakan dalam penelitian ini merupakan data yang diperoleh dari dokumentasi film "Arini" baik dalam bentuk visual ataupun naratifnya.Data sekunder yang digunakan dalam penelitian ini adalah berupa data yang berasal dari beragam dokumentasi berupa buku, tulisan di media, ataupun beragam literatur lainnya yang mendukung penelitian ini.

Teknik pengumpulan data merupakan cara peneliti agar mendapatkan data-data penelitian dengan melakukan dokumentasi dan kepustakaan.

Metode analisis dilakukan dengan analisis semiotika Peneliti menggunakan metode analisis semiotika John Fiske dalam Penelitian membutuhkan uji keabsahan data untuk mengetahui validitas dan reabilitasnya. John Fiske memperkenalkan konsep kode-kode televisi, yaitu konsep yang dapat digunakan sebagai acuan dalam memaknai tanda-tanda yang diperlihatkan. Kode-kode tersebut saling berkorelasi dalam membentuk sebuah makna tertentu. Teori yang dikemukakan John Fiske dalam The Codes of Television salah satunya adalah Level Respresentation (Respresentasi). Kode-kode sosial yang termasuk didalamnya adalah kode teknis, yang melingkupi Camera (kamera), Lighting (pencahayaan), Editing (perevisian), Music (musik) dan Sound (suara) serta kode representasi konvensional yang terdiri dari Narrative (naratif)/sound bite, Conflict (konflik) Character (karakter) , Action (aksi), Dialogue (percakapan), Setting (layar) dan Casting (pemilihan pemain).

Pada awal penelitian, penulis menonton kembali film Arini berkali-kali untuk mendapatkan sejumlah scene yang menurut penulis mengandung obyek patriarkiPenulis melakukan cut terhadap scene tersebut menggunakan fasilitas snipping tools dari perangkat komputer. Dari hasil cut tersebut akan diperoleh sejumlah scene yang kemudian akan di analisa berdasarkan teori John fiske yang telah di jelaskan diatas.

Dalam level representasi, akan dianalisa bagaimana tokoh Arini digambarkan, ditinjau dari elemen kamera dan dialog hingga pemakaian kata-kata, kalimat, atau proposi tertentu dapat membawa makna tersendiri kepada khalayak. 


\section{HASIL DAN PEMBAHASAN}

Dalam jurnal ini hanya menjelaskan makna representasi dari ketiga teori yang dikemukakan John fiske. Makna realitas adalah sebuah arti dari kenyataan yang ditampilkan dalam sebuah media yang berdasarkan dari penampilan, perilaku, nada bicara, lingkungan, riasan (Sudibyo, 2001, p. 50) .
Film Arini yang di perankan oleh Aura Kasih dan Morgan Oey disajikan dalam bentuk drama romantik. Artinya, drama yang menceritakan tentang suatu kejadian yang romantik dengan dibuat secara pendramaan. Dalam penelitian ini, penulis telah mengumpulkan beberapa scene yang hendak di analisa, yaitu:

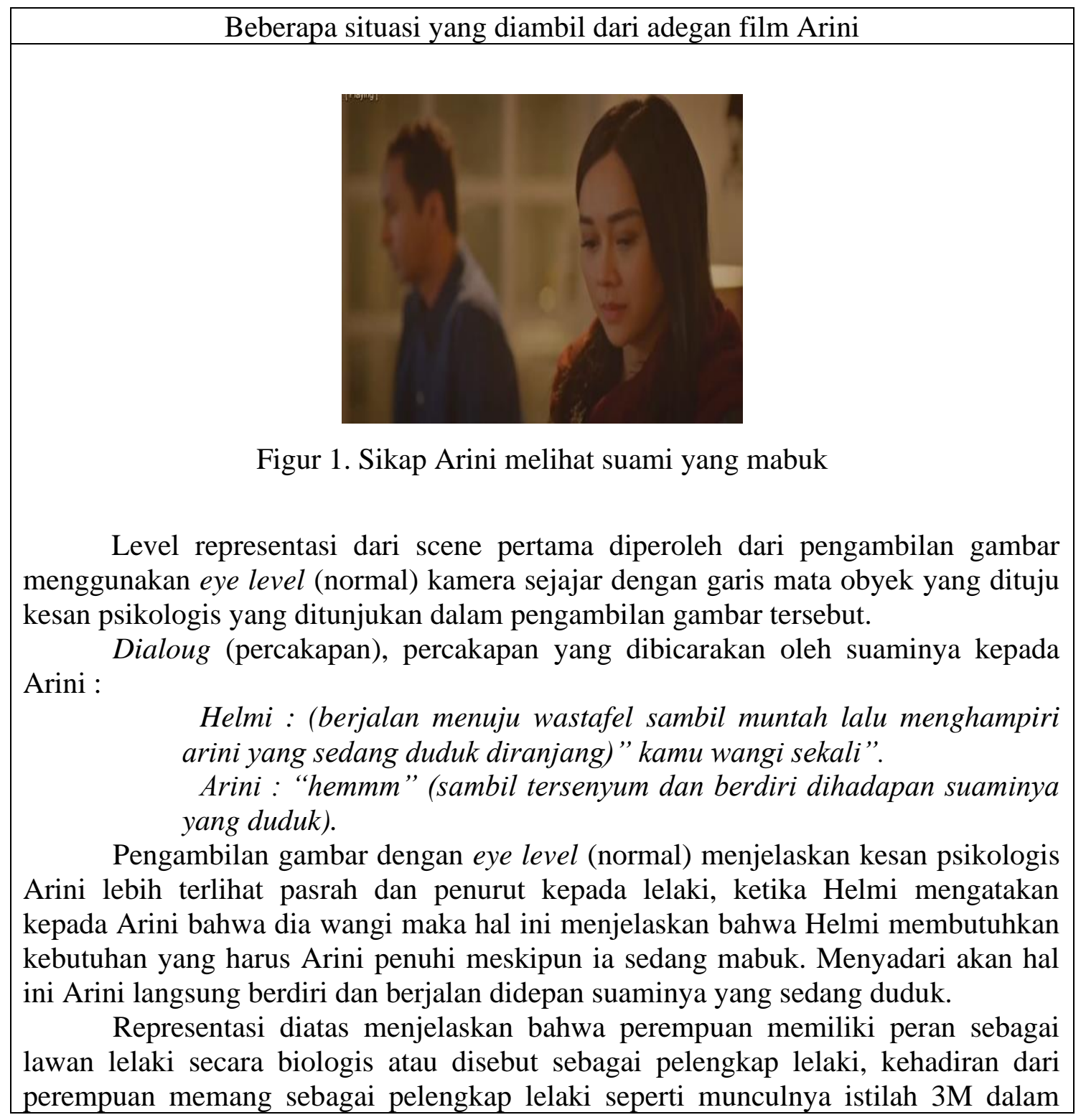


budaya di jawa yaitu perempuan haruslah memiliki peran manak (melahirkan keturunan), macak (berhias), masak (memasak), istilah-istilah tersebut sudah sangat melekat pada setiap perempuan hingga sekarang (Isma Ayu Astri Fachran, 2015).

Level representasi dari scene pertama diperoleh dari pengambilan gambar menggunakan eye level (normal) kamera sejajar dengan garis mata obyek yang dituju kesan psikologis yang ditunjukan dalam pengambilan gambar tersebut. Arini :

Dialoug (percakapan), percakapan yang dibicarakan oleh suaminya kepada

Helmi : (berjalan menuju wastafel sambil muntah lalu menghampiri arini yang sedang duduk diranjang)" kamu wangi sekali". duduk).

Arini : "hemmm" (sambil tersenyum dan berdiri dihadapan suaminya yang

Pengambilan gambar dengan eye level (normal) menjelaskan kesan psikologis Arini lebih terlihat pasrah dan penurut kepada lelaki, ketika Helmi mengatakan kepada Arini bahwa dia wangi maka hal ini menjelaskan bahwa Helmi membutuhkan kebutuhan yang harus Arini penuhi meskipun ia sedang mabuk. Menyadari akan hal ini Arini langsung berdiri dan berjalan didepan suaminya yang sedang duduk.

Representasi di atas menjelaskan bahwa perempuan memiliki peran sebagai lawan lelaki secara biologis atau disebut sebagai pelengkap lelaki, kehadiran dari perempuan memang sebagai pelengkap lelaki seperti munculnya istilah $3 \mathrm{M}$ dalam budaya di jawa yaitu perempuan haruslah memiliki peran manak (melahirkan keturunan), macak (berhias), masak (memasak), istilah-istilah tersebut sudah sangat melekat pada setiap perempuan hingga sekarang Fachran, 2015)

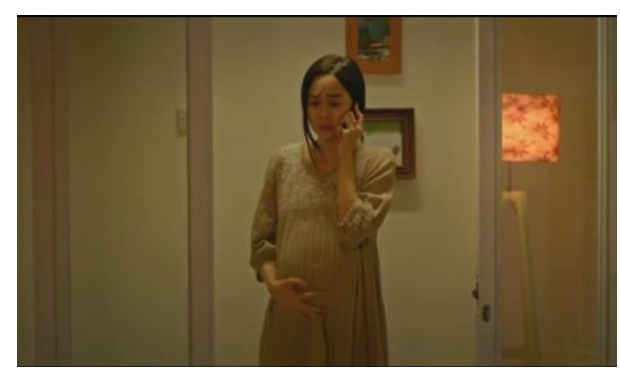

Figur 2. Arini dalam keadaan hamil

Representasi scene kedua Camera (kamera), object in frame one shot dimana pengambilan gambar seorang pemain dengan satu frame dengan mengabaikan sht size pemain tersebut menunjukan keadaan Arini sedang hamil. Dialoug (percakapan), :

Arini : halo ra..?.

Arman : bukan tante, ini Arman.

Arini: Arman, mama dimana sayang,,?

Arman : Mama lagi dibelakang sama om Helmi.

Arini : Om Helmi,? Emangnya papa kamu dimana?

Arman : kalau papa lagi di singapura (berjalan ke belakang sambil memegang telfon yang masih tersambung dengan Arini)

Ira : aku dah bilang gugurin saja dari awal

Helmi : ra, kamu jangan mutusin aku seperti ini, kamu yang minta aku pacaran sama Arini kamu yang suruh aku nikah sama Arini.

Ira : iya, tapi kamu janji engga nidurin dia 


Helmi : iyya tapi aku ngelakuinya ngga pake cinta
Arman: mah...(sambil memberikan telfon)
Ira : siapa, ? Rin rin.. Arini..
Arini : menangis tersedu.
Arini : "hemmm" (sambil tersenyum dan berdiri dihadapan suaminya
yang duduk).
Pengambilan gambar dengan object in frame one shot menjelaskan keadaan
Arini yang sedang hamil mencari suaminya dengan menelfon sahabatnya. Terdengar
percakapan antara Helmi dan Ira bahwa pernikahan Arini hanyalah kedok untuk
menutupi perselingkuhan antara mereka berdua dan mereka pun berencana untuk
menggugurkan kandungan Arini.
Pada kondisi ini, Arini mengalami bentuk opresi dari dominasi Helmi yang
awalnya mengukuhkan legitimasi patriarkinya melalui kehamilan Arini kemudian
memerintahkan Arini untuk menggugurkannya. (Sakina \& Siti A, 2017, p. 75) bahwa
realitas yang terjadi dalam masyarakat patriarki seolah membenarkan apa yang
dilakukan Helmi terhadap Arini. Masa lalu Arini dikonstruksikan sebagai perempuan
yang lemah, bisa diperdaya, dan disakiti sehingga hal tersebut kemudian membentuk
mekanisme pertahanan dirinya di masa mendatang. Hal tersebut membuat Arini akan
menjadi orang yang tertutup terhadap laki-laki yang berusaha mendekatinya dan akan
membuatnya berpikir jika semua laki-laki nantinya juga akan berbuat serupa kepada
dirinya seperti yang Helmi lakukan.

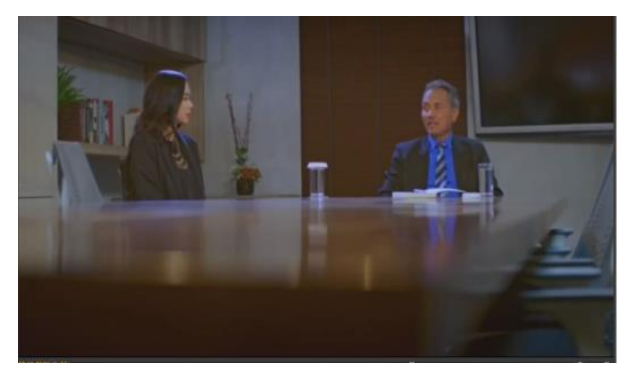

Figur 3. Arini berada dikantor sedang berdiskusi dengan pimpinan

Representasi level ke tiga menggunakan Camera establishing shot dilakukan untuk menunjukan keadaan keseluruhan dalam gambar dimana scene sedang berada diruang meeting. Dialoug (percakapan), :

Pak roso : perasaanku mengatakan bahwa sesuatu yang buruk akan terjadi disini

Arini $\quad$ : tapi saya tidak mendapat laporan apa-apa pak.

Pak roso : tidak penting siapa yang menerima laporan lebih dulu, kamu atau langsung ke aku, helmi sudah melakukan penggelapan uang perusahaan hamper dua milyar, sekarang semua aku serahkan ke kamu

Arini : serahkan ke saya pak?

Pak roso: pecat Helmi

Arini : baik

Pada scene ini menunjukan kekuasaan lelakilah yang paling berpengaruh 
dalam pengambilan keputusan dalam dunia kerja, Arini sebagai CEO di perusahaan yang memimpin berbagai divisi bahkan tidak memiliki wewenang dalam pengambilan keputusan untuk mempertahankan karyawanya sendiri hal ini sesuai dengan apa yang dituliskan (Gabriella Adipoetra, 2016) dalam jurnalnya bahwa patriarki memposisikan lelaki sebagai penguasa atas segalanya terlebih dalam keluarga namun semakin berkembangnya zaman patriarki juga sudah dilahirkan dalam wilayah umum, seperti dunia kerja yang tergambarkan dalam scene Arini meeting.

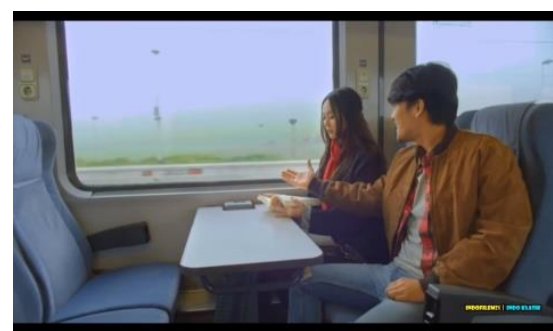

Figur 4. Arini dan Nick berada di dalam kereta api

Representasi pada scene keempat digambarkan dengan Camera (kamera), medium close up menampilkan emosi dn ekspresi pemain dengan jelas. Dialoug (percakapan), :

Nick : Thanks... so where are you going? Miss, where are you going? Hm, okay... You know I'm sorry about what just happened. It sucks when you're on holiday and running out of money. Anyway, I'm studying in London and I've planned this trip since last semester, and my last destination is supposed to be Prague. Have you ever been to Prague?

Nick : okay, let me see what you're reading.

Arini : Can I read my novel now?

Nick : You've already did without asking my permission, right? C'mon just let me see...

Arini : What do you want?

Nick : I just wanna say thank you and...he's coming back!?

Nick : So... Malaysia? Thailand? Fiji? I'm Nick... from Philippines. Nice to meet you.

Arini : Mrs. Utomo.

Nick :So, you're on vacation or something?

Adegan dalam scene ini menunjukkan bagaimana Nick melakukan pendekatan awal dari sekedar mengucapkan terima kasih, menanyakan kemana tujuannya, bertanya tentang buku yang sedang Arini baca hingga bertanya soal nama. Apa yang dilakukan Arini dalam merespon Nick secara pasif menunjukkan bagaimana budaya patriarki membentuk Arini menjadi perempuan yang cenderung pasif dan pasrah.

Arini pun dalam pertemuannya dengan Nick juga mengalami bentuk pelecehan verbal dimana Nick terlalu memaksa untuk mengetahui apa yang dilakukan Arini dalam kalimat, "You've already did without asking my permission, right?". Arini dianggap sebagai obyek untuk direndahkan dan hal tersebut dianggap sebagai 
suatu kewajaran dalam budaya patriarki dimana Nick dengan leluasa menggoda Arini. Tentu saja hal ini akan memunculkan citra dimana perempuan dianggap sebagai obyek untuk digoda dan laki-laki sebagai penggoda (Sakina \& Siti A, 2017)

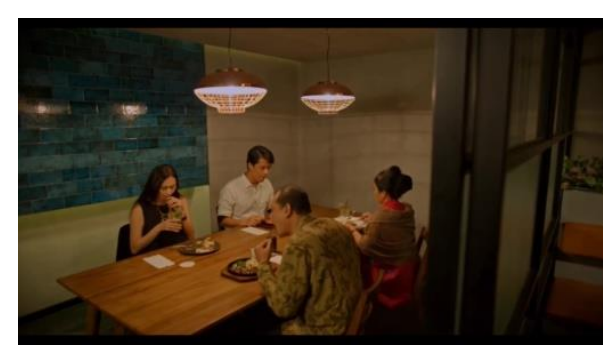

Figur 5. Arini makan malam Bersama keluarga Nick

Representasi pada scene kelima ditunjukan Camera (kamera), High angel yang digunakan dalam pengambilan gambar yang meletakkan posisi kamera diatas obyek menunjukan kesan psikologis tertekan pada obyek dalam kamera dan menunjukan situasi tegang dalam adegan film tersebut. Dialoug (percakapan),

Ibu Nick: Kata Nick, besok kamu ulang tahun ya?

Arini : Iya, bu.

Ibu Nick : yang ke berapa?

Ayah Nick : (ehem)...

Arini : 39

Ibu Nick :Begitu. Jangan panggil saya 'ibu', dong. Panggil saya 'mbak' aja.

Nick : Kalau Arini manggil mama 'mbak'. Aku juga manggil mama 'mbak', dong.

Arini : Nick!

Pada adegan scene kelima, Arini mengalami bentuk ketidakadilan gender hanya karena perbedaan usianya dengan Nick. Arini yang sudah berusia 39 tahun mendapatkan stereotip atau pelabelan negatif dari ibunda Nick yang usianya sudah 45 tahun. Menurut Ibunda Nick, Arini tidak perlu memanggilnya dengan sebutan 'ibu' melainkan 'mbak' saja sudah cukup.

Hal ini menunjukkan bahwa perbedaan usia Arini dengan Ibunda Nick tidak terlalu berbeda hanya selisih 6 tahun saja bila dibandingkan dengan menjelaskan bahwa Arini mendapatkan kesan negatif karena dirinya telah bercerai dengan mantan suaminya dan menjadikan dirinya janda sehingga orang lain akan selalu mendiskriminasi status Arini tersebut. Orang lain menilai bahwa Arini layak disalahkan karena menyandang status tersebut terlepas dari prestasi atau kedudukan yang Arini miliki. Orang tua Nick disini mewakili masyarakat patriarki(Sakina \& Siti A, 2017, p. 72) yang tidak mengetahui alasan dibalik status janda Arini. 


\section{PENUTUP}

Peneliti menemukan bahwa Arini diposisikan sebagai obyek patriarki dan mengalami dampak dari budaya patriarki, seperti dilihat dalam level representasi yang ditampilkan dalam beberapa scene mengggunakan teknik pengambilan kamera yang menjelaskan Arini wanita penurut dan lemah menjadikan Arini sebagai obyek patriarki. Terlihat pada scene ke 1,2,3,4 menjelaskan Arini sosok wanita yang lemah dan penurut akan lelaki disampingnya. Namun disisi lain, Arini ingin menyampaikan bahwa wanita merupakan wanita yang mandiri, kuat dan bebas, sehingga dia bisa memilih jalan hidupnya dan beradaptasi dengan segala situasi.

Perempuan mengalami dampak dari budaya patriarki yaitu stereotip dalam scene 5 Arini mendapatkan stereotip dari ibu Nick yang mengatakan tidak perlu memanggilnya Ibu tetapi "mbak" karena usianya berbeda 6 tahun dengan ibunya.

\section{DAFTAR PUSTAKA}

Bourdieu, P. (2001). Masculine

Domination. Standford University Press.

Christiyani Martha, S. (2017). Analisis Semiotika Representasi Kecantikan Pada Iklan Pantene Total Damage
Care 10 Versi Raline Shah di Media televisi. E-Journal Ilmu Komunikasi, Vol. 5 No.

De Beauvor, S. (2016). Second Sex Kehidupan perempuan (T. Setiawan \& N. Juliastuti (eds.)). Narasi.

Fiske, J. (2004). Cultural and Communication Studies: Sebuah pengantar paling komprehensif. Jalasutra.

Gabriella Adipoetra, F. (2016). Representasi Patriarki dalam Film "Batas." Jurnal E- Komunikasi, Vol. 4, No.

Haryono, C. G. (2017). PRAKTEK PRODUKSI HEGEMONI MILITER MELALUI FILM "JENDERAL SOEDIRMAN.” Bricolage: Jurnal Magister Ilmu Komunikasi. https://doi.org/10.30813/bricolage.v3i 01.844

Hidayat, A. (2010). Bahasa Tubuh : Tanda dalam Sistem Komunikasi. Jurnal Dakwah Dan Komunikasi, 4(2).

Isma Ayu Astri Fachran, J. (2015). Manifestasi Wanita dalam Budaya Patriarki: Ideologi dalam Serat Candraning Wanita dan Refleksi pada Iklan Era Modern. Jurnal Linguistik Terapan.

Lexy J, M. (2012). Metodologi Penelitian Kualitatif Edisi Revisi. Remaja Rosda Karya.

Moleong, L. J. (2012). Moleong, L. (2012). Metodologi Penelitian Kualitatif Edisi Revisi. Bandung: Remaja Rosda Karya. (Revisi). Remaja Rosda 
Karya.

Novarisa, G. (2019). DOMINASI

PATRIARKI BERBENTUK

KEKERASAN SIMBOLIK

TERHADAP PEREMPUAN PADA

SINETRON Domination of Patriarchi in the Form of Symbolic Violence on

Women in Soap Operas. Bricolage :

Jurnal Magister Ilmu Komunikasi.

Omara, A. (2004). Perempuan, Budaya

Patriarki Dan Representasi. MImbar Hukum II (46).

Piliang, Y. A. (2004). Semiotika Teks:

Sebuah Pendekatan Analisis Teks. In

Mediator: Jurnal Komunikasi.

Radhitya, T. V. (2019). PERAN GANDA

YANG DIALAMI PEKERJA

WANITA K3L UNIVERSITAS

PADJADJARAN. Focus : Jurnal

Pekerjaan Sosial.

https://doi.org/10.24198/focus.v1i3.2

0497

Ramadhan, F. R. (2018). "Kekerasan itu Katarsis dari Patriarki!": Resistensi pada Kekerasan terhadap Perempuan dalam Praktik Gerakan Sosial Aliansi Laki-laki Baru. Antropologi

Indonesia.

https://doi.org/10.7454/ai.v38i2.8773

Sakina, A. I., \& Siti A, D. H. (2017).

Menyoroti budaya patriarki di

Indonesia. Social Work Jurnal, Vol 7, No.

Sudibyo, A. (2001). Politik media dan pertarungan wacana (N. Huda SA (ed.)). LKiS Pelangi Aksara Yogyakarta.
Syaifullah, J. (2016). Analisis Semiotik

Tentang Kekuasaaan dan Maskulinitas pada Tampilan Website Gudang Garam Pria Punya Selera. Jurnal INFORMA Politeknik Indonusa Surakarta, Vol 1, No.

Watie, E. D. S. (2016). Representasi Wanita Dalam Media Massa Masa Kini. Jurnal The Messenger. https://doi.org/10.26623/themessenge r.v2i2.297 